\title{
LOCAL COMPOSTING IN MULTI-FAMILY HOUSES IN TOWN DISTRICTS
}

\author{
Claes B. Fransén, \\ International Compost Development, Sweden
}

\section{Introduction}

In a sustainable society based on an eco-cycling philosophy it is important to establish efficient waste recycling, as well as systems for re-use. Such systems include both material recovery and the extraction of bio-energy and nutrients using natural ecological techniques. In order to save energy and reduce transportation, which accounts for more than $60 \%$ of the waste handling costs, it is essential to develop small-scale and local systems for the recovery of nutrients from waste products.

The organic waste is an important resource of nutrients and should therefore be recycled and put back into the eco-cycling system. Every year in Sweden approximately 2,5 million tons of organic waste is not recycled, but instead incinerated or landfilled (Naturvårdsverket, 1996). From an eco-cycling point of view the organic waste should not be landfilled as most of the environmental problems during the lifetime of a landfill is shown to be connected to the organic waste. Landfill gaz, leachate, odours and hygienic problems are all a result from landfilled organic waste, which instead ought to be composed or digested (Naturvårdsverket, 1996).

Investigations have shown that over $75 \%$ of mixed solid household waste is biologically degradable and that nearly $50 \%$ can be composted and re-used as a nutritious top-soil additive. Therefore, a recent Directive from the European Community prescribes that at least $75 \%$ of the household waste in Europe shall be recycled and re-used by year 2005 .

\subsection{General definition of composting}

Aerobic composting of solid waste is mostly employed to produce soil-improving agents. A general definition of composting for the production of soil improver is the biological decomposition and stabilisation of organic substrates, under conditions that allow the development of thermophilic temperatures as a result of biologically produced heat, to produce a final product that is stable, free from pathogens and plant seeds, and can be beneficially applied to land (Haug, 1993).

During the composting process organic matter is used as an energy source by microorganisms, and after the uptake of oxygen, hydrocarbons are converted to carbon dioxide, water and metabolites such as ammonia, sulphur compounds and a less degradable rest, 
normally called humus. During the process heat is emitted. The turn-over time for the composting process is dependent on parameters such as moisture, temperature, oxygen supply and ratios between different chemical constituents, for example the $\mathrm{C} / \mathrm{N}$ ratio (Warfvinge, 1997).

\subsection{Reasons for local composting}

A big interest has been focused on local composting for several reasons:

- in order to avoid transport and handling of a significant waste fraction which implement several environmental inconveniencies, such as health danger for the handling staff, spreading of fungal spores and inconvenient odours, spreading of leachate into the ground water.

- in order to be able to collect the household waste less often and thus create a substantial economy for the community.

- in order to diminish waste combustion, which is estimated to produce approximately $75 \%$ of the dioxine in the world.

- because composted material is more easy, hygienic and economic to store, handle and transport than untreated waste.

- because of the volume reduction of approximately $90 \%$

- from an eco-cycling point of view.

\subsection{Actual techniques for aerobic composting}

The most common techniques are based on various types of open composting, such as windrows or mattresses of different shapes and sizes. The windrows can be optimised with active air injection. The volume of the compost usually determines the rate of compost production (Hogland, 1999).

Since several years a multiple choice of composting equipments has been introduced on the market, both for local composting and central large-scale composting. All the installations for local composting, which are more or less sophisticated, work horizontally and often present either inconveniencies for the users or a relatively poor function. Another factor, common to these composting machines, is that a relatively large amount of sawdust must be added to the waste in order to obtain a suitable $\mathrm{C} / \mathrm{N}$ ratio and moisture degree. As sawdust takes a long time to break down the quality of the final product thus suffers. It also appears that these composting units, mostly because of a low capacity, bring the costs highly above the municipality rates for traditional waste treatment.

Taking into consideration the above and, especially the market situation, International Compost Development (ICD) was created in spring 1997 in order to further develop a 
composting machine, which technology was based on a new and revolutionary concept, called vertical under composting.

\section{International Compost Development}

The company is based in the town of Lund, where the proximity to the university and high technology institutions has given interesting possibilities to develop the product. In the beginning of 1998 a research and development program was put in place together with the university and with a financial contribution from the Knowledge and Competence Foundation, managed by Teknopol in Lund. Since then the engineer team of ICD, together with professor William Hogland, has performed full-scale tests, both in the laboratories of the university and in residential areas.

The production of the machines is situated in the south of Sweden and is performed on a serial basis since december 1998.

The company actually employs 4 persons, but by including the Swedish sales network and the production lines over 25 persons are involved with the product.

The business idea of ICD was defined as follows:

Propose to the market a competitive, economically defendable, user friendly and environmental solution for the local waste treatment, that minimizes the needs of waste transports as well as handling and landfill costs.

\section{Research \& Development}

\subsection{Market demands}

When getting closer to the market the ICD team found several criteria, that always were emitted in connection with composting. Consequently, the research, when developing the vertical composting unit, was based on and took into consideration these market demands, such as:

- local composting must be an economically interesting alternative to traditional waste treatment, at least in a near future

- the composting unit shall not be too space demanding, but have a good capacity/size ratio

- the composting unit must be very user friendly

- the composting unit must be highly automatic in order to avoid a time-consuming and costly maintenance work with it

- the use of sawdust is considered inconvenient and should be avoided, if possible

- composting must not be equivalent to inconvenient odours

- the composting process shall not involve any transportation of fungus spores 
- the composting unit shall rapidly produce a nutritious top-soil additive of good quality without any needs of processing outside the unit

\subsection{Vertical under compostinge-a new concept}

For several reasons it seems that the vertical under composting technique, if constructed according to the different criteria governing the composting process, is a very interesting alternative to the existing horizontal techniques.

As a matter of fact, the thermophilic microorganisms can break down the waste into compost humus in 48 hours when the conditions are optimal. One of the most important parameters then is the oxygen supply, which has become one of the most crucial innovation parts of the ICD Vertical Composting Unit.

After thorough developing and tests the ICD team has found efficient solutions to all the market demands mentioned above:

- the ICD Vertical Composting Unit keeps the costs of waste treatment at a level of approximately $1.400 \mathrm{SEK}$ per ton

- the ICD Vertical Composting Unit, that can take care of the organic waste of more than 100 households, only needs $1 \mathrm{sqm}$ of space and fits into most existing waste spaces

- the ICD Vertical Composting Unit is very easy to use: 1) open grinder outlet lid, 2) put in paper bag with organic waste, 3 ) close the lid. The machine does the rest of the work.

- the ICD Vertical Composting Unit is fully automatic - except for the filling. The average maintenance time is calculated to less than one hour per week.

- no sawdust or other carbonic stabilizers is needed for the process with the ICD Vertical Composting Unit as the user puts the waste in to a compostable paper bag, which is thrown directly into the grinder of the machine. As the organic household waste keeps a $\mathrm{C} / \mathrm{N}$ ratio of approximately 20-25 (Gustaf Alm, 1991) the addition of the paper bag is sufficient in order to create a perfect balance for the composting process. It is further interesting to observe that the quality of the final compost is of a very high nutritous standard already after only approximately one week. Laboratory tests at Agrolab Scandinavia in Kristianstad of Sweden shows that the extraded compost is fully broken down and that the NPK values are higher than in all composts from other comparable composting systems.

- composting with the ICD Vertical Composting Unit has shown, as well in laboratory tests as in full-scale residential tests, that no odours are incurred, except for the start-up period of 2-3 weeks. This is obtained mainly because of the continuous air-flow (oxygen) through the compost material, that avoids the creation of non-oxygenized pockets in the material.

- the closed system and the oxygen flow of the ICD Vertical Composting Unit avoids all transportation of fungus spores. Further, limited and unnecessary contact with the process material limits the risks of human contact with eventual fungus spores.

- the vertical undercomposting method, together with the construction principles of the ICD 
Vertical Composting Unit, makes it possible not to mix new waste with already processed material in the unit. This enables a maturing process inside the composting machine and results into a fully broken down compost material (top-soil additive) coming out from the unit.

\section{New governmental goals for the treatment of household waste}

The Swedish government has in a waste proposition established some basic goals for the future waste treatment in Sweden (Naturvårdsverket, 1996):

- the contents of health- and environmental dangerous substances in the waste shall be minimized by measures in the production lines

- the volume of the waste shall be minimized through measures both in the production lines and the consumption lines

- the waste shall be recycled and re-used as much as possible

- very high environmental standards shall be demanded on the treatment of non-recycled waste.

In order to accomplish these goals the future waste treatment shall not be bound to a single technical solution. New and successive better alternatives therefore shall be developed.

\subsection{Fixed governmental measurements}

The most important operative goals established by Naturvårdsverket concerning the future waste treatment are:

- the handling and the treatment of the waste shall be performed in such way that the negative effects on the environment will be avoided

- a better treatment of the waste shall be obtained through source-separation of the waste.

- before year 2000 all waste producing activities shall be increasingly informed about waste volume, flows and waste diminishing measurements

- before year 2000 the consumer knowledge about waste treatment shall be increased through information and education

- land filled household waste shall diminish by $50 \%$ by 2000 and $70 \%$ by 2005

- organic household waste shall not at all be land filled after year 2005.

\subsection{Biological waste treatment}

Fundamentally most of the organic waste shall be composed or digested. However, there still is a risk that the costs of biological waste treatment make these methods non-competitive with 
combustion. Therefore, economical measurements, e.g. taxes on waste combustion or on landfilled waste, can put the biological treatment into a more competitive situation (Naturvårdsverket, 1996). The first step has been taken with the landfill tax of $250 \mathrm{SEK}$ per ton, that will be put in place from January 2000.

\section{Local composting of household waste in multi-family houses}

The average Swedish household, estimated to 2,3 persons, produces around $1000 \mathrm{kgs}$ of waste per year. Out of this waste approximately $330 \mathrm{kgs}$ or 600 liters are compostable organic waste. For reasons, already mentioned above, it seems more and more evident that this waste fraction should not be transported from the production source, but instead taken care of locally. The only possibility then is composting.

\subsection{Source-separation of the waste - a condition for composting}

Between $75-85 \%$ of the household waste is biologically degradable and a substantial economy can be obtained for the multi-family communities if an efficient source-separation in to different fractions is made locally. Consequently, local spaces for the source-separated waste more and more play an important role in multi-family house areas. The tenants or the owners, private or public, negociate the waste handling costs with the waste management companies and the municipalities in order to finance a better local environment policy. Diminishing the volume of the waste by local composting thus becomes more and more interesting.

In order to obtain a good quality of the compost humus and be able to re-use it as a top-soil additive the users of a composting machine must source-separate the waste in the households. This is also important for the proper functioning of the composting units.

Environmentally dangerous materials, as batteries, drugs, thermometers, chemicals, etc, must be avoided and, therefore, extracted by the households and deposited at areas specially created by the municipalities for this type of waste.

Finally, the combination of composting and source-separating into different bio-degradable fractions has become a logical solution to reach the established governmental goals.

\subsection{Consumer education}

When introducing composting into the multi-family communities it has been shown by fullscale residential tests that a very important part of a successful result resides in the education of the tenants. Their interest and motivation for composting, source-separation of the waste and a better local environment is essential in order to obtain a satisfactory result and a good functioning of these relatively new waste treatment methods. It is, therefore, of utmost importance to educate and stimulate the users of a composting machine, not only about how it functions, but also why they shall change their manners and point out the advantages of such a change. Therefore, nearly all unsuccessful introductions of composting and sourceseparation can be related to a failure in the education and motivation of the tenants in the area and not to the method or system put in place. 
It is also very interesting to state that very often the middle-age community is more difficult to motivate than the third age and, especially, the children community. Also, socio-cultural factors can play an important role when introducing these new methods of waste management.

\subsection{Consumer advantages}

It is essential to establish and make clear to the consumers of these new methods about the benefits that follow. Already, has been mentioned above that economical advantages can be obtained. These may result in lower rent, or at least a maintained rent, for the tenants. But there are also other interesting benefits, such as:

- a better local environment, with less odours and other inconveniencies related to the waste, especially when the collection of the waste is performed each fortnight, as is the case in a lot of municipalities today

- the possibility to obtain a nutritous top-soil additive free of charge for flower pots, balcony cultivations, gardens, etc.

It has also been stated that the introduction of composting in multi-family house areas creates a certain community relationship and mutual responsibility that generate a profitable social climate among the tenants.

\section{Conclusions}

Composting of organic household waste, that was prohibited in Sweden for nearly forty years, has lately proven to be an important factor in modern waste management. Economically, environmentally and also socially, this ancient method of waste treatment surely has come back to stay. Even if it disturbs the financial interests of the waste management companies.

\section{References}

Alm G. (1991) Kompostboken, LTs förlag, pp. 54

Haug R.T. (1993) The practical Handbook of Compost Engineering, Lewis Publishers, Ann Arbor,pp. 717

Hogland W. (1999) Optimized composting of source-separated organic fractions of household waste in a vertically fed reactor system, Seventh International Waste Management and Landfill Symposium, Sardinia '99

Naturvårdsverket (1996) Aktionsplan Avfall, Rapport 4601, pp. 65-72, 134-135

Warfvinge T. (1997) Environmental Chemistry, Environmental Science in a Biogeochemical Perspective, KFS in Lund AB, pp. 277 